\title{
Vulnerability Analysis to Prioritize the Reconstruction of Earthquake Affected Drinking Water Systems
}

\section{P. Gurung and C. Adhikari}

Abstract: In 2015, two massive earthquakes occurred in the central region of Nepal, killing more than 8000 people. The disaster destroyed many houses and public infrastructures and severely affected 14 districts in the central region of Nepal. Most of the affected people were disconnected from basic services such as safe drinking water. Being a basic human need, essential to live a healthy life, drinking water scheme rehabilitation project was initiated by many non-governmental agencies in coordination with the Government of Nepal (GoN). However, due to the limitation of the funds and time, most of the implementing agencies faced problems to prioritize schemes and the communities, which at first needed to focus to reinstate. Therefore, a vulnerable ranking method was adopted to distinguish the priorities to reconstruct damaged and totally destroyed water schemes in Dhading, Gorkha, Nuwakot, and Rasuwa districts of Nepal, which are the districts in the most earthquake affected region. In the process of vulnerability ranking, three major community level parameters and indicators were considered for the ranking. 1) Number of households without safe drinking water after an earthquake, 2) Number of households without improved sanitation after an earthquake, and 3) Disadvantage Group (DAG) ranking of the Village Development Committees (VDCs) of the districts. This process of ranking using community level parameters technique is able to substantiate a justice scientifically in front of the communities, government, donor, and other stakeholders in the selection of VDCs to rehabilitate the drinking water schemes.

Keywords: Disaster, Earthquake, Water Scarcity, Safe Drinking Water, Vulnerability, Decision Support, Nepal

\section{Introduction}

$\mathrm{T}$ the world, the common issues of water resources that 1 are faced during post-earthquake are; degradation in the quality of water in river, reduction in the discharge capacity of the sewerage system, increased amount of sediments in the river, decreased flow of sources of drinking water, and disappearing of existing spring water sources and appearing in new places (Barr et al. 2012; Brears 2012; ECRC 2011; SAVE 2016). This means earthquake affects both surface and ground water resources, which affects the water demand for domestic consumption. Additionally, the earthquake has degraded and/or changed the physical habitat of the flora and fauna, and then the local ecological system (ARSCC 2012; Barr et al. 2012). Damage of physical infrastructures, loss of human life and property, landslides, floods, volcanoes and tsunami are others shocking effects in postearthquake (Ammon 2001; Barr et al. 2012; Grandin et al. 2015).

On 24th April and 12th May of 2015, two massive earthquakes of Magnitude 7.8 and 6.7 momentmagnitude-scales $\left(V_{\psi} \mathbb{V}_{\psi}\right)$ respectively, occurred in the central part of Nepal and killed more than 8000 people, injured more than 22,000 people, destroyed more than 600,000 houses, and damaged about 300,000 houses (ACTalliance 2016; Adhikari et al. 2015; CARE 2016a; DoMG 2015; LGCDP 2015a; NPC 2015a, b; UNICEF 2015). This tremor has destroyed many houses and community infrastructures and severely affected 14 districts in the central and western development region of Nepal (NPC 2015a, b; UNICEF 2015). The epicentre of first earthquake was at Barpak village of Gorkha district and the second was near to the Chinese border with Nepal in Dolakha district (Adhikari et al. 2015; NPC 2015a, b). The main shock was followed by hundreds of aftershocks, which has also affected some physical infrastructures and mental health of the people (Adhikari et al. 2015; NPC 2015a, b).

\section{Impact of Earthquake on the Drinking Water and Sanitation}

In Nepal, the earthquakes of 2015 has affected people of 14 districts by partially and totally disconnecting them from the basic services; such as safe drinking water facilities and sanitation services (NPC 2015a, b; UNICEF 2015). The earthquake has damaged and destroyed the structural components of existing drinking water systems and sanitation facilities, which has affected the hygiene practices due to lack of safe drinking water and destroyed latrines for defecation. In 14 most affected districts, about 1,570 among the 11,288 drinking water schemes were completely destroyed and 3,663 schemes need to be repaired and maintained to rehabilitate; and about 2.2 million household latrines were totally destroyed (CARE 2016a; LGCDP 2015a; NPC 2015a, b). In addition, the earthquake has affected the water availability in the water sources in many ways: such as reduced water yield in the drinking water sources, disappearance of water in the sources, and contamination of drinking water due to damage and destruction of the water structure and landslides (NPC, 2015a, b).

\section{Study Area (Working Districts)}

This study has been carried out in four districts among the earthquake affected 14 districts of Nepal. The working districts; Dhading, Nuwakot, and Rasuwa districts lie in the central development region of Nepal; and Gorkha in the western development region. As 
mentioned earlier, the epicentre of earthquake on 24 April 2015 with magnitude $7.8 M_{\mathrm{w}} M_{\mathrm{u}}$ was in the Barpak village of Gorkha district and other working districts are adjoining with Gorkha. This might be a major reason, the working districts were highly affected by that earthquake, and the losses in the districts were supplemented by a major aftershock (with $6.7 M_{w} M_{m}$ ) on 12 May 2015 (NPC 2015a, b). Figure 1 shows the location of the working districts and all the districts, which were affected by earthquakes. Among the 14 earthquake affected districts, Dhading is in 8th, both Gorkha and Nuwakot are in 6th, and Rasuwa is in the 3rd rank of the most destroyed houses. Dhading is in 3rd, both Gorkha and Nuwakot are in $5^{\text {th }}$, and Rasuwa is in the 4th rank of the most human causalities (CARE 2015, 2016a, b; DCA 2015; NPC 2015a, b; SAVE 2016). According to the data collected from the Water Supply and Sanitation Division (WSSD) office of the districts, about 2,501 drinking water schemes and 22,693 households were damaged by the earthquakes (refer to Table 1), which caused an increase in open defecation and personal hygiene behaviour became worse (ACTalliance 2016; CARE 2015, 2016a, b; DCA 2015; LGCDP 2015a; SAVE 2016).

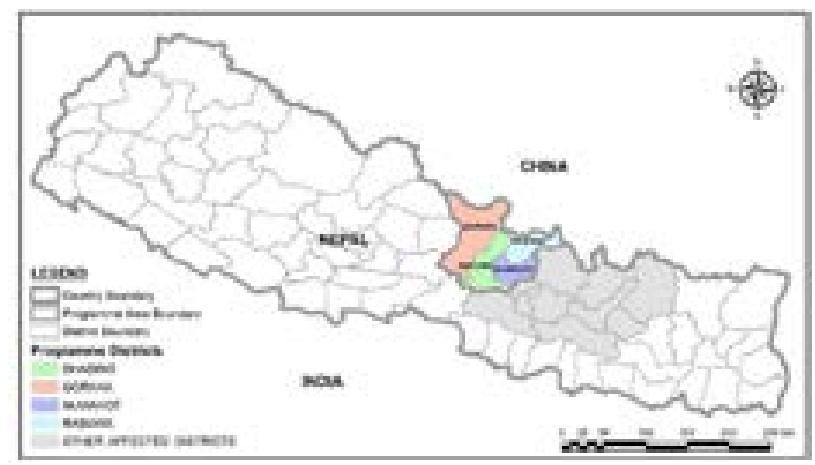

Figure 1: Location Map of the Working Districts

\section{The Challenges of Reconstruction}

Due to the earthquakes, most of the affected people were disconnected from the basic services; such as safe drinking water and sanitation facilities. Safe drinking water is a basic human need to live a healthy life, thus the drinking water scheme rehabilitation project was initiated by many non-governmental agencies in coordination with the Government of Nepal (GoN), communities, WASH cluster and other stakeholders (NPC 2015a, b; UNICEF 2015). In the earthquake affected regions, most activities of the development and humanitarian projects were focused on the recovery and re-construction of disaster resilient community infrastructures (ACTalliance 2016; CARE 2016a). Recovery and re-construction were the mandate and top most priority of the Government of Nepal, and also of donors and all of implementing agencies. Among the implementing agencies, the consortium members (CARE International, Save the Children, and DanChurchAid
(DCA)) of the project have also aimed to rehabilitate the drinking water schemes in their working VDCs, which was 43 among 189 VDCs and Municipalities within working districts (CARE 2016a). Although, the project has focused only in the VDCs, not in Municipalities, because people of rural communities were more vulnerable than people of urban centres in post-earthquake stage. However, the project was not able to cover all the VDCs of the working districts due to limitation of funds, short time period to accomplish rehabilitation, and requirements of quick supports (CARE 2015, 2016a, b; DCA 2015; SAVE 2016). This problem was mostly faced by many agencies, who were involved in recovery and re-construction activities. Thus, the prioritization of VDCs to support, was a big challenge to the agencies, who were working to rehabilitate the destroyed and damaged drinking water schemes. Same was the case for prioritizing the most vulnerable communities at first, to reinstate their infrastructures and supplies that were destroyed and damaged by earthquake.

Therefore, this vulnerable ranking method carried out under this study has been used to distinguish the priorities to reconstruct partially and totally destroyed water schemes in Dhading, Gorkha, Nuwakot, and Rasuwa districts. These working districts are also most vulnerable districts due to the earthquakes. In the process of vulnerability ranking, three major community level parameters and indicators were considered for the ranking; which were 1) Number of households without safe drinking water after an earthquake, 2) Number of households without improved sanitation after an earthquake, and 3) Disadvantage Group (DAG) ranking of the Village Development Committees (VDCs) of the districts. DAG is a ranking based on the concentration of disadvantaged groups in the VDCs, which is in five groups based on the seven different indicators (CARE 2016a; Inlogos 2009; LGCDP 2015b).

\section{Material and Methods}

\section{Data and Sources}

This study is based on the data collected from the District Disaster Relief Committee (DDRC) and other districts authorities (NPC 2015a, b); from the statistics of Nepal National Population Statistics Census 2011; and need assessments reports of the consortium members (ACTalliance 2016; CARE 2015, 2016a, b; DCA 2015). Table 1 represents the aggregated demographic data of the working districts and effect of the earthquake on the people of the district, which includes damage of houses, drinking water systems and sanitation facilities, and loss of human life. In addition to these data, Disadvantaged Group (DAG) of the Villages Development Committees (VDCs) and Municipalities of the working districts were collected (refer to Figure 2) (LGCDP, 2015a, b). 


\begin{tabular}{|l|c|c|c|c|}
\hline & Dhading & Gorkha & $\begin{array}{c}\text { Nuwa- } \\
\text { kot }\end{array}$ & $\begin{array}{c}\text { Ra- } \\
\text { suwa }\end{array}$ \\
\hline $\begin{array}{l}\text { No. of VDCs/Munici- } \\
\text { palities }\end{array}$ & 47 & 62 & 62 & 18 \\
\hline Number of Households & 88,542 & 74,107 & 59,190 & 9,741 \\
\hline Population & 483,578 & 387,552 & 266,367 & 42,133 \\
\hline $\begin{array}{l}\text { Number of House de- } \\
\text { stroyed }\end{array}$ & 75,261 & 65,214 & 52,087 & 9,351 \\
\hline $\begin{array}{l}\text { Number of People died } \\
\text { Number of Water Sup- } \\
\text { ply Schemes before } \\
\text { earthquake }\end{array}$ & 7,160 & 1,305 & 1,536 & 204 \\
\hline $\begin{array}{l}\text { Number of Household } \\
\text { with access to water } \\
\text { supply before earth- } \\
\text { quake }\end{array}$ & 62,433 & 45,736 & 47,556 & 2,227 \\
\hline $\begin{array}{l}\text { Number of Water Sup- } \\
\text { ply Scheme Damaged } \\
\text { by earthquake }\end{array}$ & 787 & 673 & 943 & 98 \\
\hline $\begin{array}{l}\text { Number of Household } \\
\text { Latrines before earth- } \\
\text { quake }\end{array}$ & 53,009 & 74,107 & 35,690 & 7,360 \\
\hline $\begin{array}{l}\text { Number of Household } \\
\text { Latrine Damaged by } \\
\text { earthquake }\end{array}$ & 37,054 & 46,029 & 26,074 & 5,594 \\
\hline
\end{tabular}

represents the water schemes that were destroyed/ damaged by the earthquake. Similarly, Figure 4 (left) represents the number of household latrines that existed in the VDCs/Municipalities in the working districts, and Figure 4 (right) represents latrines destroyed/damaged by the earthquake.

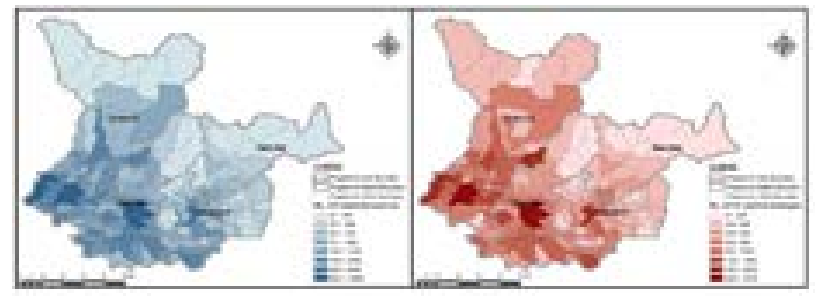

Figure 4: Number of Household Latrines before Earthquake (left) and Destroyed/Damaged by Earthquake (right) in VDCs of the Working districts

\section{Parameters for the Vulnerability Rank}

Based on the collected data of the VDCs and Municipalities, number of households without safe drinking water and the number of households without improved sanitation after an earthquake were identified and quantified with respective percentages. Additionally, ranking of the Disadvantage Group (DAG) of the VDCs and Municipalities (refer to Figure 2) was also considered in this study to map the vulnerability rank. The technical experts' team from the consortium members of the project (CARE International, Save the Children, and DanChurchAid (DCA)); has jointly worked to identify the weightage to the different parameters and indicators. Table 2 represents the percentage weightage of the parameters, which were considered for this study. The DAG ranking was on 5 categories; I, II, 3A, $3 \mathrm{~B}$ and IV, which signify very low, low, medium, high and very high concentration of DAG, respectively (refer to Figure 2 and Table 2 (a))(Inlogos, 2009, LGCDP, 2015b).

\begin{tabular}{|c|c|}
\hline & Weightage \\
\hline \multicolumn{2}{|l|}{ a. Disadvantage Group (DAG) Ranking } \\
\hline I (Very Low Concentration of DAG) & $5 \%$ \\
\hline II (Low Concentration of DAG) & $7 \%$ \\
\hline 3A (Medium Concentration of DAG) & $25 \%$ \\
\hline 3B (High Concentration of DAG) & $28 \%$ \\
\hline IV (Very High Concentration of DAG) & $35 \%$ \\
\hline \multicolumn{2}{|l|}{ b. Status of Water and Sanitation System } \\
\hline $\begin{array}{l}\text { Percentage of Households without safe water after } \\
\text { earthquake }\end{array}$ & $60 \%$ \\
\hline $\begin{array}{l}\text { Percentage of Households without improved sanitation } \\
\text { after earthquake }\end{array}$ & $5 \%$ \\
\hline Weightage of DAG Ranking in Percentage & $35 \%$ \\
\hline
\end{tabular}

Figure 3 and Figure 4 represent the status of the drinking water schemes and household latrines in the working districts. Figure 3 (left) represent the number of drinking water schemes that existed in the VDCs/ Municipalities before the earthquake, and Figure 3 (right)

Table 2: Percentage Weightage of the Parameters and Indicators for Vulnerability Rank Mapping

This project was designed to rehabilitate the drinking water schemes destroyed by the earthquake. Therefore, 
the parameters such as; destroyed houses and human casualties were not considered for this vulnerability ranking. The maximum weightage of $60 \%$ was considered for the parameter households without safe drinking water facilities after an earthquake, because the primary objective of the project was to restore drinking systems (refer to Table 2). In Nepal, disadvantaged groups such as; poor, socially excluded people, ethnic minority etc. (LGCDP 2015a, b) were educationally, economically and socially marginalized communities. These communities become most vulnerable due to poor health condition and lack of easy access to basic needs and services. So that, the weightage of $35 \%$ was considered for the DAG ranking (refer to Table 2). Consequently, only 5\% of weightage was given to the households without improved sanitation services. The final vulnerability ranking was quantified based on the conceptual framework that is presented in Figure 5. This framework is partially based on the conceptual framework developed by National Adaptation Programme of Action (NAPA) to Climate Change (for detail refer to (MoE, 2010)). However, all the parameters and indicators that were included in NAPA were not considered for this rank mapping. Additionally, the project has planned to reach poor, vulnerable and socially excluded (PVSE) community within the working VDCs, and also planned to reach out female and elderly headed households within targeted communities (CARE 2016a). This was a major reason for considering the DAG in this rank mapping.

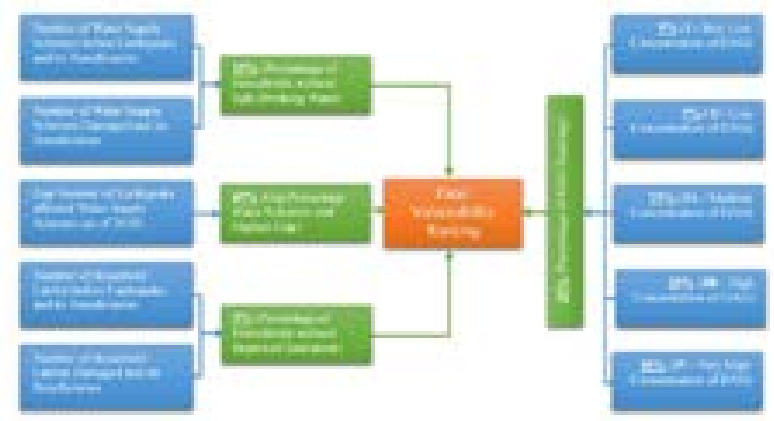

Figure 5: Conceptual Framework of the Vulnerability Rank Mapping

\section{Results and Discussion}

\section{Vulnerability Ranking Map of Working Districts}

In the working districts, the damaged houses were $85 \%, 88 \%, 88 \%$, and $96 \%$; the damaged drinking water schemes were $68 \%, 52 \%, 61 \%$, and $48 \%$; and the damaged sanitation services were $70 \%, 80 \%, 73 \%$, and $76 \%$ respectively in Dhading, Gorkha, Nuwakot, and Rasuwa (refer to Table 1). Figure 6 represents the percentage of the households, which were disconnected from the safe drinking water and improved sanitation facilities due to the earthquake. Figure 6 (left) shows that people in some of the highest affected VDCs do not have access to safe drinking water $(100 \%)$ after the earthquake and in the lowest affected VDCs, about $18 \%$ households do not have access to safe drinking water. Similarly, Figure 6 (right) shows similar kinds of status, some highly affected VDCs do not have any access to the improved sanitation facilities after the earthquake, and in the lowest affected VDCs, about $23 \%$ of households do not have access to the improved sanitation facilities. These figures also show that VDCs in Gorkha district were highly affected by the earthquake by damaging a maximum number of sanitation facilities, whereas damaged/destroyed status of the water schemes were not distributed uniformly in the VDCs of working districts.

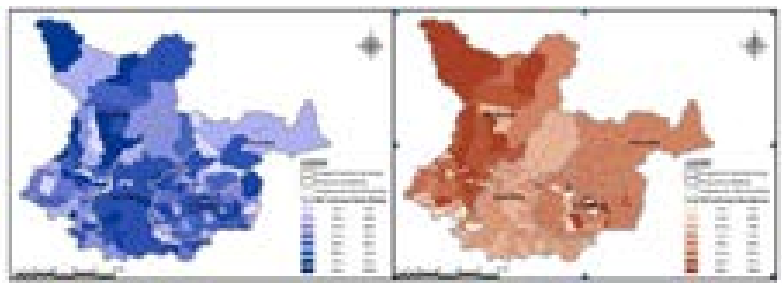

Figure 6: Percentage of Households without Safe Drinking Water (left) and Improved Sanitation Services (riaht) after Earthquake

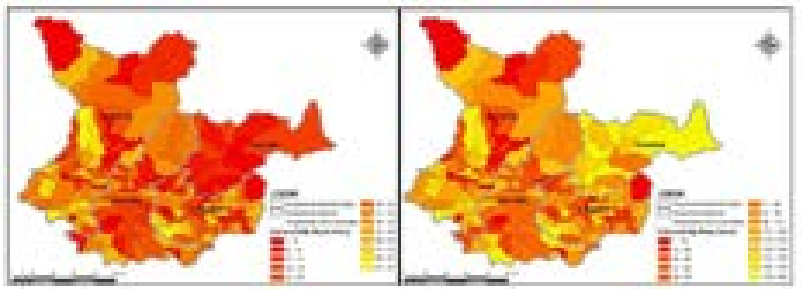

Figure 7: Final Vulnerability Rank Maps of Intra-District Comparison (left), and Inter-Districts Comparison (right) of the VDCs/Municipalities in the Working districts

The combined final vulnerable maps were prepared by considering the parameters and respective weightage mentioned in Table 2 and in the conceptual framework of Figure 5, which were the combined product of Figure 2 and Figure 6. Thus, Figure 7 represents the final combined vulnerable maps, where most vulnerable VDC is represented by smallest number 1 and the vulnerable rank goes in ascending order with lesser vulnerable VDC. Thus, the highest number represents the lowest affected VDC by the earthquake. Figure 7 (left) signifies intraVDCs comparison ranking within a district. So that, the ranking of VDCs in one district were independent with a ranking of VDCs in other districts, which means similar colour of VDC in different districts might have different percentage of vulnerability rank. Whereas, Figure 7 (right) signifies inter-VDCs comparison ranking between the VDCs in all four working districts, in which similar colour of VDCs carried out equal percentage of vulnerability. These two different maps have supported the project to select the working VDCs within a district and to perceive the comparative status with other districts. 


\section{Vulnerability Rank Status Analysis of the Working VDCs}

As mentioned before, target of the project was to support the communities and VDCs, which were most vulnerable and where no agencies were working for the reconstruction of that community. So that, this vulnerability tool was used as a decision-making tool to select the working VDCs in the working districts. Therefore, ranks in percentage of all the VDCs were plotted against the percentage ranks of the working VDCs and presented in Figure 8. In the plot, the linear trend line of households without safe drinking water services in Figure 8 (Left) shows that average trend was higher in the working VDCs than the average trend of all the VDCs of the working districts, which signifies project's reach was comparatively more to the higher vulnerable communities. Inversely, plot of linear trend line of households without improved sanitation facilities (Figure 8 (Middle)) and concentration of disadvantaged group (Figure 8 (Right)) in the working VDCs were lower than the average trend of all the VDCs of the working districts, which signifies the project's reach was comparatively more to the lower vulnerable communities. However, this discrepancy was obtained due to the weightage given to the parameters and indicators to quantify percentage of the vulnerability ranking, where maximum weightage of $60 \%$ was given to the households without safe drinking water services and the other two weightages were in total, $40 \%$. The result of the vulnerability rank was also supported by the statistics presented in Table 3, which was comparative average statistics of the percentage ranks of all the VDCs and only working VDCs of the working districts. Consequently, these comparative statistics also show that the average rank was $64 \%$ in working VDCs, which was slightly higher than the average rank of all the VDCs, that was $63 \%$.
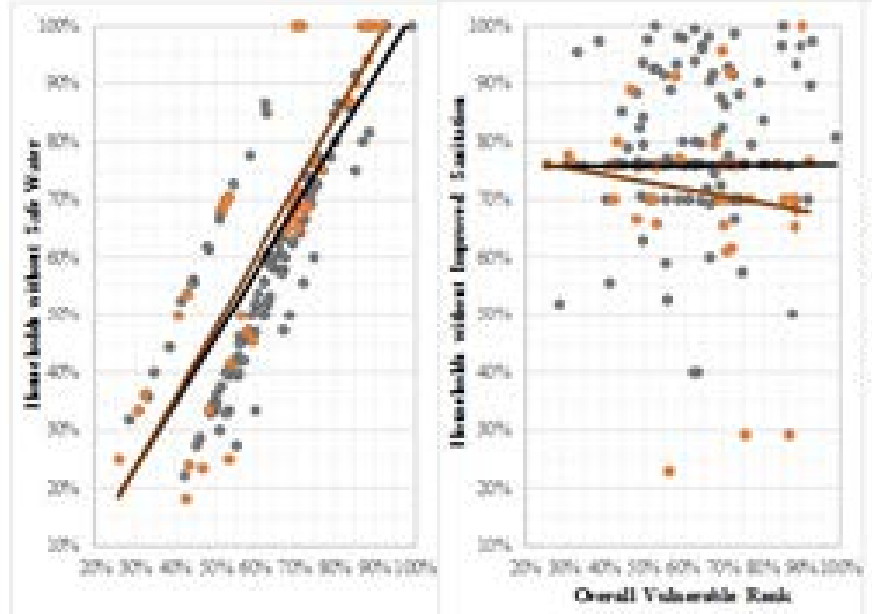

Figure 8: Plots for the Percentage of Households without Safe Water (Left), without Improved Sanitation (Middle) and DAG Ranking (Right); their Correlation with Overall Vulnerable Rank

\begin{tabular}{|l|l|l|}
\hline & $\begin{array}{l}\text { All of } \\
\text { VDCs }\end{array}$ & $\begin{array}{l}\text { Working } \\
\text { VDCs }\end{array}$ \\
\hline $\begin{array}{l}\text { Damaged/Destroyed Houses (percentage of } \\
\text { total houses) }\end{array}$ & $83 \%$ & $92 \%$ \\
\hline $\begin{array}{l}\text { Human Casualties (percentage of total popu- } \\
\text { lation) }\end{array}$ & $0.23 \%$ & $0.16 \%$ \\
\hline $\begin{array}{l}\text { Households without improved water after } \\
\text { earthquake }\end{array}$ & $61 \%$ & $65 \%$ \\
\hline $\begin{array}{l}\text { Households without improved sanitation after } \\
\text { earthquake }\end{array}$ & $76 \%$ & $71 \%$ \\
\hline DAG Ranking in Percentage & $25 \%$ & $25 \%$ \\
\hline Overall Vulnerable Rank & $63 \%$ & $64 \%$ \\
\hline
\end{tabular}

Table 3: Comparison between Effect of the Earthquake in all the Working VDCs and all of VDCs in Working Districts

\section{Conclusions}

This study was outcome of small exercise that has been done to plan and implement community-based water and sanitation project, especially, selecting the communities and working VDCs in the districts. This vulnerable ranking technique was a small exercise, but it was found to be significantly useful in making an important decision to categorize the VDCs and communities for implementation of developmental activities. This technique was based on actual damage of existing community infrastructures, which provided daily basic services and facilities to the people of earthquake affected regions; their access to the safe drinking water and sanitation facilities; socioeconomic status of the village and communities; and the logical mathematical and statistical quantification. Therefore, this technique was found socially and scientifically justifiable. Moreover, this technique of ranking, using community level parameters and indicators, was able to substantiate a justice logically in front of the communities, government, donor, and

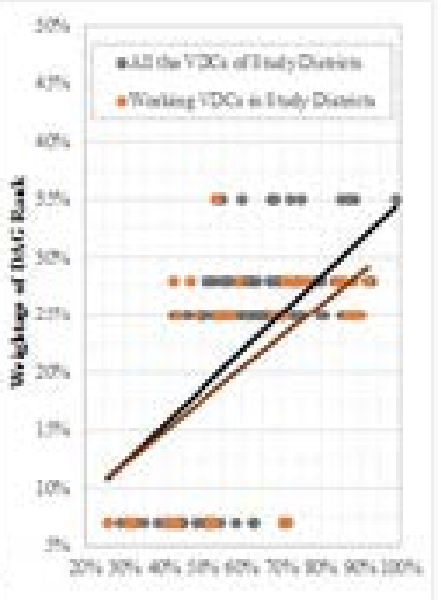

other stakeholders with regards to selecting VDCs and communities to rehabilitate the drinking water schemes and improved sanitation facilities. By this exercise, the project was able to reach out and plan for developmental 
activities to the most vulnerable VDCs and communities in the recovery and re-construction stage after the mega earthquakes of 2015 in Nepal.

\section{Acknowledgement}

We would like to express special thanks to project NPL161 team of DanChurchAid (DCA) for helping us collect the data from the fields, and other senior personnel from the DCA Nepal Office; Regional Representative, Head of Program, Regional Funding Coordinator, Head of Finance, and Regional Programme Officer; for their encouragement and motivation to complete this study. In addition, we are truly grateful to the representative from the CARE International and Save the Children Nepal Country office to provide their expert advices on this study and providing essential data from the fields, without them it would have been almost impossible to standardize this study. We also would like to thank all the internal reviewers from DCA for their thoughtful insights, helpful comments and suggestions. At last, but not the least, our sincere gratitude goes to the organizers of the conference 'Water Security and Climate Change: Challenges and Opportunities in Asia'; to the editors and co-editors of the conference proceedings; and to all the management team of the conference.

P. Gurung and C. Adhikari are associated with DanChurchAid (DCA), Kathmandu, Nepal.

\section{Corresponding address: pabitra.gurung@gmail.com}

\section{References}

ACTalliance. (2016) Project Report: Nepal Earthquake Recovery, Reconstruction and Resilient (3R) NPL161. Kathmandu, Nepal.

Adhikari, L. B., Gautam, U. P., Koirala, B. P., Bhattarai, M., Kandel, T., Gupta, R. M., Timsina, C., et al. (2015) The aftershock sequence of the 2015 April 25 Gorkha-Nepal earthquake. Geophys. J. Int.203(3), 2119-2124. Oxford University Press. doi:10.1093/ gji/ggv412

Ammon, C. J. (2001) Earthquake Effects (Shaking, Landslides, Liquefaction, and Tsunamis). Dep. Geosci. Penn State Univ. Retrieved September 28, 2016, from http://eqseis.geosc.psu.edu/ cammon/ HTML/Classes/IntroQuakes/Notes/earthquake_ effects.html

ARSCC. (2012) Post-Quake Ecology of the Lower Avon River: Current State of the Fish and Invertibrate Community. Palmerston, New Zealand: Aquatic Research \& Science Communication Consultants.

Barr, N., Zeldis, J., Gongol, C., Drummond, L. \& Scheuer, K. (2012) Ecological effects of the Canterbury earthquakes on Avon-Heathcote Estuary / Ihutai macroalgae. Wellington, New Zealand.
Brears, R. (2012) The effects of the earthquake on urban freshwater resources in Christchurch. Am. Int. J. Contemp. Res.2(10), 145-149.

CARE. (2015) Multi-sectoral needs assessment conducted in the areas of Gorkha, Dhading and Sindhupalchowk. Kathmandu, Nepal.

CARE. (2016) Project Report: Rapid Community WASH Recovery. Kathmandu, Nepal.

CARE. (2016) Baseline Survery Report (Draft) for DEC Emergency Reponse for Communities Affected by Nepal Earthquake Phase II Project. Kathmandu, Nepal.

DCA. (2015) Needs Assessment Report in Dhading, Lamjung and Makawanpur Districts. Kathmandu, Nepal.

DoMG. (2015) Information on Earthquake in Nepal. Nepal Seismol. Centre, Dep. Mines Geol. Minist. Ind. Gov. Nepal. Retrieved September 28, 2016, from http://www.seismonepal.gov.np/

ECRC. (2011) Earthquake impacts on groundwater. Christchurch, New Zealand: Groundwater Resources Section, Environment Canterbury, Regional Council. Retrieved from http://ecan.govt. $\mathrm{nz} /$ publications/General/earthquake-impactsgroundwater-update-1-130411.pdf

Grandin, R., Vallée, M., Satriano, C., Lacassin, R., Klinger, Y., Simoes, M. \& Bollinger, L. (2015) Rupture process of the $\mathrm{M} \mathrm{w}=7.92015$ Gorkha earthquake (Nepal): Insights into Himalayan megathrust segmentation. Geophys. Res. Lett.42(20), 83738382. doi:10.1002/2015GLo66044

Inlogos. (2009) Assessment of Village Development Committee Governance and the Use of Block Grants. Kathmandu, Nepal: Institute of Local Governance Studies, Ministry of Local Development and United Nations Development Programme.

LGCDP. (2015) Summary Report: Nepal Emergency Response of LGCDP-II. Kathmandu, Nepal.

LGCDP.(2015) NEPAL: Concentration of Disadvantaged Group (DAG) Map. Kathmandu, Nepal.

MoE. (2010) National Adaptation Programme of Action (NAPA) to Climate Change. Kathmandu, Nepal: Ministry of Environment, Government of Nepal.

NPC. (2015) Nepal Earthquake 2015: Post Disaster Needs Assessment, Vol. B: Sector Reports. Kathmandu, Nepal: National Planning Commission, Government of Nepal. Retrieved from http:// www.worldbank.org/content/dam/Worldbank/ document/SAR/nepal-pdna-executive-summary. pdf

NPC. (2015) Nepal Earthquake 2015: Post Disaster Needs Assessment, Vol. A: Key Findings. Kathmandu, Nepal: National Planning Commission, Government of Nepal.

SAVE. (2016) Pre-WASH Knowledge, Attitude nad Pratice (KAP) in Rasuwa and Nuwakot. Kathmandu, Nepal.

UNICEF. (2015) Nepal earthquake humanitarian situation report three months review. Kathmandu, Nepal. 